\title{
BMJ Open Social work leadership competencies in health and mental healthcare: a scoping review protocol
}

\author{
Amina Hussain (1) , Rachelle Ashcroft
}

To cite: Hussain A, Ashcroft R. Social work leadership competencies in health and mental healthcare: a scoping review protocol. BMJ Open 2020;10:e038790. doi:10.1136/ bmjopen-2020-038790

- Prepublication history and supplemental material for this paper are available online. To view these files, please visit the journal online (http://dx.doi 038790).

Received 24 March 2020 Revised 13 August 2020 Accepted 06 September 2020 org/10.1136/bmjopen-2020-

\section{ABSTRACT}

Introduction Leadership skills are an integral part of effective social work practice in health and mental healthcare settings. Social workers require critical leadership skills to effectively support, treat and advocate for the complex needs of those most vulnerable. Despite an increasing focus on social work leadership within the last decade, there has been a paucity of research on socia work leadership competencies within the realm of health and mental health service provision. To bridge this gap, this scoping review will synthesise and map the current literature on social work leadership competencies in health and mental healthcare.

Methods and analysis Arksey and 0'Malley's five-stage framework for scoping reviews will guide our search of six academic databases including: PsycINFO, OVID Social Work Abstracts, OVID Medline, Sociological Abstracts, Social Services Abstracts and CINAHL Plus with Full Text. Selected articles that meet inclusion criteria will then be reviewed and charted. Recurrent themes will be reviewed through a qualitative thematic analysis, and reported in both text and figures.

Ethics and dissemination Findings will highlight key social work leadership competencies as they relate to social work practice, team dynamics, and client outcomes within health and mental healthcare. Material retrieved in this scoping review was selected from publicly available sources, and thus as an obtrusive research method, this review does not warrant ethics approval. Findings from this review will be disseminated through published scholarly material, as well as presented at conferences pertaining to social work research, practice and education.

\section{Check for updates}

\section{(c) Author(s) (or their} employer(s)) 2020. Re-use permitted under CC BY-NC. No commercial re-use. See rights and permissions. Published by BMJ.

Factor-Inwentash Faculty of Social Work, University of Toronto, Toronto, Ontario, Canada

\section{Correspondence to} Amina Hussain; amina.hussain@mail.utoronto. ca

\section{INTRODUCTION}

Leadership skills are an integral part of effective social work practice in health and mental healthcare settings. Social workers employed in hospitals, primary care, community and mental health organisations require leadership skills to effectively support, treat and advocate for the complex needs of those with mental illness, multiple health challenges, and those most vulnerable and/or marginalised. ${ }^{1-13}$ The changing landscape of healthcare service provision has resulted in a growing need for leadership from social workers in both health and

\section{Strengths and limitations of this study}

This is the first comprehensive scoping review on social work leadership competencies for health and mental healthcare, providing an opportunity to merge findings and inform social work practice in these domains.

- The search strategy was developed in consultation with two University of Toronto librarians, as well as faculty members that have expertise in this research area.

- The inclusion criteria for articles are limited to those in English only.

- Literature included in this scoping review will not be formally appraised for quality.

- This scoping review will include all article types and methodologies, but will not include books or grey literature.

mental healthcare settings. ${ }^{6-14}$ Formally and informally, social workers practising within interdisciplinary teams display leadership skills when engaging in crisis management, providing critical family support, developing treatment plans, resolving complex decisions to support clients and when collaborating with multiple service providers. ${ }^{3-7}$ There exists a breadth of diversity in the nature of social work roles, expectations, and skill sets within the realm of health and mental healthcare across North America. Social work roles within health and mental health can vastly differ based on the organisational contexts in which social workers are situated in, as well as the political, economic, societal and cultural factors impacting roles in these domains. ${ }^{3-11}$ Yet, an overarching commonality between social workers in both health and mental health settings is that they are situated in key positions to bridge medical models of care with behavioural health, recovery-oriented and client-centred approaches to support their clients. ${ }^{1-14}$ These require key leadership competencies to advocate for and prioritise client needs within a service delivery culture 
that is often compelled to meet corporate, organisational and political pressures. ${ }^{4-9}$ 14-19

As the delivery of health and mental health services strives towards a value-based system, there will be a continued need for social workers to engage in formal and informal leadership roles to advocate for clientcentred care. ${ }^{2-14}$ Previous research has highlighted the importance of leadership skills in increasing staff retention, effectiveness, team cohesion and reducing burnout among interdisciplinary team members, including social workers. ${ }^{10-13}$ There has also been research on social workspecific leadership competencies and the importance of recognising these as integral components of social work practice. ${ }^{14}{ }^{15}$ The development of tools to assess leadership competency has become increasingly common within healthcare. Competency is often defined as holding the 'ability, skills or knowledge to complete one's tasks efficiently'. ${ }^{20}$ Within health and mental healthcare, the development of competencies for the assessment of leadership includes the Multifactorial Leadership Questionnaire ${ }^{22}$ and the Service Leadership Behaviour Scale. ${ }^{23}$ At present, there is an existing framework developed by the Network for Social Work Management ${ }^{24}$ that outlines 21 key competencies for social work managers in formal leadership positions related to executive leadership, resource management, strategic management and community collaboration. Although this framework is widely used to guide training of social work students intending to pursue management and leadership positions in the human services sector, ${ }^{24}$ it does not specify key competencies for clinical social workers in health and mental health settings. Thus, developing standardised social work leadership competencies responds to a need to better prepare social workers for the increasingly complex patient care needs within health and mental health settings. ${ }^{11-14}$

Given the increasing number of social workers in both informal and formal positions of leadership, there has been a continued need to advance social work leadership skills to support social work practice within health and mental healthcare. ${ }^{5-12}$ Yet, a critique in the literature is the consistent lack of focus on social work leadership among social work programmes in North America. ${ }^{5-8} 1819$ This is mirrored in the mental health literature, in which there is a large focus on clinical social work skills that often neglect the importance of social work leadership as a practice-based skill. ${ }^{151819}$ Despite an increasing focus on social work leadership within the last decade, and the prominence of formal and informal social work leadership roles in both health and mental healthcare organisations, there is a paucity of research on the importance of social work leadership competencies as they relate to effective social work practice within the realm of health and mental health service provision. ${ }^{718}{ }^{19}$ Moreover, at present there does not exist a scoping review mapping the social work leadership competencies within either of these domains. Thus, it is unclear what the overarching leadership competencies are for social workers in either domain, and what differences may exist across the two domains. There is also a lack of research on how social work leadership skills impact client experiences and utilisation of health and mental health services. ${ }^{7} 1819$ The relationship between social work leadership in health and mental healthcare, and how this may impact client outcomes warrants further research exploration. In order to bridge this gap within social work education, practice and research, this scoping review aims to synthesise and map the current literature on social work leadership competencies within health and mental healthcare. The review will also highlight any overarching leadership competencies that support social workers practising in health and mental healthcare, as well as identify domainspecific leadership competencies. Identifying leadership competencies that are specific to either health or mental health domains, as well as associated practice and organisational settings, is a key anticipated finding of this scoping review. This would serve beneficial in addressing these research gaps in the social work literature.

A key focus of this review is also to identify effective social work leadership competencies that may improve health and mental health service provision in North America. These objectives will be addressed through the following research questions: (1) What are essential social work leadership competencies for effective social work practice in health and mental healthcare? (2) What social work leadership competencies are outlined as supportive for clients and families seeking treatment within health and mental health settings? (3) How do social work leadership skills support effective service delivery, team decision-making, team dynamics and social workers' provision of care? and (4) What are key recommendations for improving social work leadership competencies among social workers practising in health and mental health settings? Findings will also serve beneficial for a comparative analysis of leadership competencies presented in the Human Services Management Competencies framework, and contribute towards the expansion of this framework. ${ }^{24}$

At present there is no unanimous definition of social work leadership used in existing literature, yet some common attributes can be noted across definitions. In the field of leadership studies there are numerous existing definitions of leadership, shaped by both the field of scope being referenced as well as the theoretical orientation of those defining the term. ${ }^{25-28}$ Warren Bennis, an expert in the field of leadership studies, defines leadership as, 'having vision that is well communicated among the team, establishing trust and taking action to propel leadership potential'. ${ }^{29}{ }^{30}$ Another definition of leadership refers to 'a process of social influence that motivates others in achieving their identified goals'. ${ }^{27} 28$ One definition of leadership in social work is 'the ability of a social work leader to demonstrate professionalism, confidence, credibility, clear goal setting, solution-focused problem-solving, and effective collaboration to support and empower others' ${ }^{28}$ This is the definition of social work leadership that guides this scoping review. However, 
it is crucial to recognise that the nuanced definitions of leadership warrant critical exploration of the theoretical challenges and assumptions that arise in generating a unified definition of this term. To elaborate, how leadership is conceptualised is founded on one's understanding of leadership as an individual or an organisational attribute. This is often rooted in the sociocultural contexts of the literature. ${ }^{1819} 2531-35$ The growing body of leadership research is situated within the individualistic culture of the Western world, guiding conceptualisations of leadership as individual rather than organisational or collective traits. ${ }^{18-21} 25$ This dismantles the recognition of leadership as a collective shared process and how leadership may present in different sociocultural settings.

Moreover, the epistemological underpinnings of the authors also guide how this term is and has historically been defined. ${ }^{18} 1925$ The majority of leadership literature in the last two decades is based within a North American context, and focuses on leadership within the US military, with the dominant discourse of leadership attributes founded on White hegemonic masculinity. ${ }^{18} 1925$ These discourses perpetuate leadership traits as qualities held by those in select positions of power. Moreover, these assumptions underpinning the literature not only inform one's understanding of what leadership is and should be, but also reject the recognition of alternative forms of leadership characteristics (collective leadership, leadership traits encompassed by all genders and leadership qualities displayed by different ethnic populations). ${ }^{18} 19$ 25-27 These methodological and theoretical challenges underlying the leadership literature may also contribute to the existing lack of focus on leadership within social work research. The theoretical challenges of conceptualising and defining social work leadership (which populations and identities are privileged when discussing social work leadership competencies) warrants further exploration. Thus, this protocol will also map out how social work leadership is defined in the literature, and conclude with discussion on the theoretical and epistemological challenges that are embedded in these findings.

\section{METHODS AND ANALYSIS}

This scoping review aims to identify and synthesise the current literature on social work leadership competencies within the realm of health and mental healthcare in North America. Given the breadth of existing research on leadership in different domains, a scoping review is suitable to address the abovementioned research questions and strategically map findings as they relate to social work leadership within health and mental healthcare. ${ }^{36}$ This includes both formal (professional practice leader, executive director, manager) and informal (clinical roles such as discharge planner, case manager, therapist, hospital social worker, forensic social worker) positions of leadership that social workers may occupy. In this review, health and mental health settings include both non-profit and for-profit organisations including hospitals, community mental health clinics, primary healthcare, transitional support and residential care, forensic settings, academic/ school-based settings and any other independent community programmes that focus on providing health or mental healthcare. This review will not focus on social work practice in child protection services, group home/assisted living centres, nor legal settings, though the researchers recognise the significant role of social workers within these contexts. This protocol will follow the five-stage scoping review framework by Arksey and O'Malley ${ }^{37}$ which includes: (1) outline the research questions of interest; (2) identify relevant studies; (3) select studies that meet inclusion criteria; (4) chart data/key results; (5) synthesise and report findings. ${ }^{37}$ This review will abide by the Preferred Reporting Items for Systematic Reviews and Meta-Analyses Extension for Scoping Reviews guidelines, which can be referenced in online supplemental appendix A. ${ }^{38}$ It is intended that through addressing the identified research questions, the scoping review will provide findings as they relate to social work research, practice, and policy to improve social work leadership within health and mental health settings.

\section{Stage 1: Outline the research questions}

The research questions emerged after completion of a literature review on social work leadership within North America. The following research questions were developed by the main author (AH) and reviewed by the second author (RA).

1. What are essential social work leadership competencies for effective social work practice in health and mental healthcare?

2. What social work leadership competencies are recognised as supportive for clients and families seeking treatment within health and mental healthcare settings?

3. How do social work leadership skills support effective service delivery, team decision-making, team dynamics and social workers' provision of care?

4. What are key recommendations for improving social work leadership competencies among social workers practising in health and mental health settings?

\section{Stage 2: Identify relevant studies}

The search strategy (outlined in table 1) was developed by the first author (AH) in consultation with the second author (RA). The final search strategy was revised and formatted in consultation with two librarians at the University of Toronto. The following six databases were selected: PsycINFO, OVID Social Work Abstracts, OVID Medline, Sociological Abstracts, Social Services Abstracts and CINAHL Plus with Full Text. These databases were chosen due to their relevance to the field of social work, health and mental health education, social work research and practice, interdisciplinary healthcare, as well as related to leadership within the domain of healthcare. To enhance the scope and breadth of our findings, a hand search of the references from relevant articles was 


\begin{tabular}{|c|c|}
\hline \# & Searches \\
\hline 1 & $\begin{array}{l}\text { exp Social Workers/ or exp Social Work/ or "social } \\
\text { work*".mp. }\end{array}$ \\
\hline 2 & $\begin{array}{l}\text { exp Leadership/ or exp Leadership Qualities/ or } \\
\text { exp Leadership Style/ or leader*.mp. }\end{array}$ \\
\hline 5 & exp Health/ or Health.mp. \\
\hline 6 & $\begin{array}{l}\text { mental health/ or community mental health } \\
\text { services/ or community psychiatry/ or mental } \\
\text { health programs/ or mental health services/ }\end{array}$ \\
\hline 3 & competenc $^{\star} . \mathrm{mp}$. or exp Competence/ \\
\hline 7 & capacity.mp. \\
\hline 8 & exp Ability/ \\
\hline 9 & skill.mp. \\
\hline 10 & $\begin{array}{l}\text { (competenc }{ }^{\star} . m p . \text { or exp Competence/) OR } \\
\text { (capacity.mp.) OR (exp Ability/) OR (skill.mp.) }\end{array}$ \\
\hline 11 & $\begin{array}{l}\text { (exp Health/ or Health.mp.) OR } \\
\text { (mental health/ or community mental health } \\
\text { services/ or community psychiatry/ or mental health } \\
\text { programs/ or mental health services/) }\end{array}$ \\
\hline 12 & $\begin{array}{l}\text { (exp Social Workers/ or exp Social Work/ or "social } \\
\text { work*".mp.) } \\
\text { AND (exp Leadership/ or exp Leadership Qualities/ } \\
\text { or exp Leadership Style/ or leader*.mp.) AND } \\
\text { (competenc*.mp. or exp Competence/) OR } \\
\text { (capacity.mp.) OR (exp Ability/) OR (skill.mp.)] } \\
\text { AND((exp Health/ or Health.mp.) OR (mental health/ } \\
\text { or community mental health services/ or community } \\
\text { psychiatry/ or mental health programs/ or mental } \\
\text { health services/)) }\end{array}$ \\
\hline 13 & $\begin{array}{l}\text { (exp Social Workers/ or exp Social Work/ or "social } \\
\text { work*".mp.) } \\
\text { AND (exp Leadership/ or exp Leadership } \\
\text { Qualities/ or exp Leadership Style/ or leader*.mp.) } \\
\text { AND((competenc*.mp. or exp Competence/) OR } \\
\text { (capacity.mp.) OR (exp Ability/) OR (skill.mp.)) } \\
\text { AND((exp Health/ or Health.mp.) AND (mental } \\
\text { health/ or community mental health services/ or } \\
\text { community psychiatry/ or mental health programs/ } \\
\text { or mental health services/)) }\end{array}$ \\
\hline
\end{tabular}

conducted. Articles that included our outlined search terms in their title, keywords or abstract were selected and compiled into a document for initial review. Amongst these articles, those that reference leadership competencies in any form (relevance to skills training, leadership abilities, leadership capacity), as well as focus explicitly on service provision, include allied health team members and are relevant to the field of mental health or healthcare will be included for a title and abstract screening.

Due to changing healthcare contexts ${ }^{1-9}$ and the evolution of leadership theories over the last few decades, ${ }^{39-42}$ this scoping review will include literature published between 2005 and 2020. This timeframe will allow us to retrieve findings as they pertain to social workers' roles within the most current health and mental health contexts. Any material that was published before 2005 was excluded from further review. Additional inclusion criteria include articles published within the context of North America only. The nature and role of social work practice may differ depending on one's geographical location and associated political, economic, societal and healthcare system needs. Thus, this study will focus on the continent of North America where there is largely uniformity in the nature and roles of social workers within health and mental healthcare.

\section{Stage 3: Select studies that meet inclusion criteria}

After compiling a complete list of relevant articles from the aforementioned databases, a review of the article title and abstract will be conducted by the main author $(\mathrm{AH})$ alongside a second reviewer (AK). The selected articles from the first review will then require a full-text review to ensure that their content meets the required inclusion criteria. The second author (RA) will resolve any questions or discrepancies during both stages of review. The online platform Covidence will be used to support efficient screening, article review and charting during this process.

In order for articles to be selected for the initial title and abstract screening, they must meet the following inclusion criteria: must be published after 2005, written in English only and focus on a North American context only. Relevant material can include literature or systematic reviews, teaching notes, conceptual or theoretical papers, and empirical research. Books, book chapters, commentaries, editorials, thesis dissertations, grey literature and book reviews will be excluded. Additionally, all articles must include the following terms within their title or abstract: leader and/or leadership, and health or mental health in some form of the word. The content of the abstract must meet the following inclusion criteria: (1) explicitly focus on service providers in some capacity, including allied health workers such as social worker, human service worker or interdisciplinary team members (2) have an explicit focus on the realm of health, healthcare services and/or mental healthcare within the abstract, and (3) explicitly focus on leadership skills as they relate to service provision. Also, the abstract content must focus on social work practice within the following settings: hospitals, community mental health clinics, primary care, transitional support and residential care settings, forensic settings, academic/ schoolbased settings and any other independent community programmes that focus on providing health or mental healthcare. Settings such as child protection services, group home/assisted living centres, nor legal settings will be excluded during the initial review.

Full-text screening will involve the inclusion of articles that specifically discuss implications for social work research, education or practice. Papers that focus on 'emerging leaders', including biographies or editorials will be excluded. Moreover, material that does not 
include a full abstract or a full-text version online will be excluded.

\section{Stage 4: Chart data/key results}

Identified themes from the chosen articles will be charted to present their content as it relates to the research questions. Content will be reviewed and charted under the following headings: authors, year of publication, country where article was published, and/or country the research focuses on, name of journal, format of paper, leadership competencies identified, service providers referenced in article, outlined implications for social work, area of focus (health, mental health), settings/care services focused on, focus on marginalised, female-identified or cross-cultural leadership skills, outlined benefits of social work leadership, outlined benefits for clients seeking health and/ or mental healthcare, and recommendations for implementing social work leadership competencies. This will involve an iterative process in which charted categories will be reviewed and modified throughout this process, in order to ensure that categories appropriately capture the breadth and inclusiveness of article findings. Any discrepancies or difficulties in the charting process will be resolved collaboratively between both authors, and other faculty members may be consulted for further revision. A University of Toronto librarian who specialises in scoping reviews will also be consulted to support the charting process.

\section{Stage 5: Synthesise and report findings}

The charted findings will be displayed via summary tables in the appendices. In addition, a qualitative thematic analysis of these outlined findings will be conducted to present recurrent themes from the literature. Themes will be presented visually through graphs particularly on social work leadership competencies identified, service provision settings/domains highlighted, and findings on the impact of social work leadership on client outcomes and service utilisation. The complete scoping review will be disseminated as published scholarly material, as well as through poster format at relevant social work conferences. It is anticipated that findings identify and outline the importance of social work leadership, and its relevance within current social work education, research and practice. This scoping review is also intended to highlight key leadership competencies for effective social work practice in health and particularly mental healthcare. Findings will also support the advancement of effective service provision for client-centred care, as well as highlight the importance of teaching social work leadership competencies within social work programmes in North America.

\section{Patients and public involvement}

There were no patients, clients or members of the public involved in any aspect of this project.

\section{ETHICS AND DISSEMINATION}

The scoping review outlined in this paper aims to map and synthesise the current literature on social work leadership competencies, particularly within the realm of health and mental healthcare. The findings retrieved in this scoping review were selected from publicly available sources, and thus as an obtrusive research method this review does not warrant ethics approval. Findings from this review will be disseminated through published scholarly material, as well as presented at conferences pertaining to social work research, practice and education.

Contributors AH developed the research questions, wrote and edited the protocol in consultation with RA. AH developed the search strategy in consultation with two independent librarians at the University of Toronto. Modifications to the search strategy were done through continuous feedback from these sources. RA critically reviewed the final protocol prior to submission to BMJ Open.

Funding The authors have not declared a specific grant for this research from any funding agency in the public, commercial or not-for-profit sectors.

\section{Competing interests None declared.}

Patient and public involvement Patients and/or the public were not involved in the design, or conduct, or reporting, or dissemination plans of this research.

Patient consent for publication Not required.

Provenance and peer review Not commissioned; externally peer reviewed.

Open access This is an open access article distributed in accordance with the Creative Commons Attribution Non Commercial (CC BY-NC 4.0) license, which permits others to distribute, remix, adapt, build upon this work non-commercially, and license their derivative works on different terms, provided the original work is properly cited, appropriate credit is given, any changes made indicated, and the use is non-commercial. See: http://creativecommons.org/licenses/by-nc/4.0/.

ORCID iDs

Amina Hussain http://orcid.org/0000-0002-8697-0360

Rachelle Ashcroft http://orcid.org/0000-0002-5666-1946

\section{REFERENCES}

1 Guo KL, Company JD. Leaders in hospital-based social work: the roles and functions of directors of social work in the case management model. Leadersh Health Serv 2007;20:124-33.

2 McGregor J, Mercer SW, Harris FM. Health benefits of primary care social work for adults with complex health and social needs: a systematic review. Health Soc Care Community 2018;26:1-13.

3 Saxe Zerden Lde, Lombardi BM, Jones A. Social workers in integrated health care: improving care throughout the life course. Soc Work Health Care 2019;58:142-9.

4 Ashcroft R, Van Katwyk T, Hogarth K. An examination of the holism paradigm: a view of social work. Soc Work Public Health 2017;32:461-74.

5 Jones B, Phillips F. Social work and interprofessional education in health care: a call for continued leadership. J Soc Work Educ 2016;52:18-29.

6 King Keenan E, Sandoval S, Limone C. Realizing the potential for leadership in social work. J Soc Work 2019;19:485-503.

7 Mizrahi T, Berger CS. A longitudinal look at social work leadership in hospitals: the impact of a changing health care system. Health Soc Work 2005;30:155-65.

8 Xenakis N. The role of social work leadership: Mount Sinai care, the accountable care organization, and population health management. Soc Work Health Care 2015;54:782-809.

9 Dobrof J, Bussey S, Muzina K. Thriving in today's health care environment: strategies for social work leadership in population health. Soc Work Health Care 2019;58:527-46.

10 Carpenter J. Mental health recovery paradigm: implications for social work. Health Soc Work 2002;27:86-94.

11 Cohen JA. Managed care and the evolving role of the clinical social worker in mental health. Soc Work 2003;48:34-43.

12 Corrigan PW, Lickey SE, Campion J, et al. Mental health team leadership and consumers satisfaction and quality of life. Psychiatr Serv 2000;51:781-5.

13 Davidson G, Brophy L, Campbell J. Risk, recovery and capacity: competing or complementary approaches to mental health social work. Australian Social Work 2016;69:158-68. 
14 Hoge MA, Stuart GW, Morris J, et al. Mental health and addiction workforce development: federal leadership is needed to address the growing crisis. Health Aff 2013;32:2005-12.

15 O'Brien A-M, Calderwood KA. Living in the shadows: a Canadian experience of mental health social work. Soc Work Ment Health 2010;8:319-35.

16 Shera W. Managed care and people with severe mental illness: challenges and opportunities for social work. Health Soc Work 1996;21:196-201.

17 Viator RE. The relevance of transformational leadership to nontraditional accounting services: information systems assurance and business consulting. J Info Systems 2001;15:99-125.

18 Holosko M. Social work leadership: identifying core attributes. J Hum Behav Soc Environ 2009;19:448-59.

19 Rank MG, Hutchison WS. An analysis of leadership within the social work profession. J Soc Work Educ 2000;36:487-502.

20 Brownell J, Goldsmith M. Commentary on "meeting the competency needs of global leaders: A partnership approach": An executive coach's perspective. Human Resource Management 2006;45:309-36.

21 Mumford TV, Campion MA, Morgeson FP. The leadership skills strataplex: leadership skill requirements across organizational levels. Leadersh Q 2007;18:154-66.

22 Bass BM, Avolio BJ. MLQ multifactor leadership questionnaire: duplication set. Redwood City. Mind Garden: CA, 2000.

23 Shek DT, LK M, Ma C, et al. Convergent and factorial validation of the service leadership behavior scale. International Journal of Child and Adolescent Health 2018;11:479.

24 Hassan A, Wimpfheimer S. Human services management competencies. A guide for public managers. USA: The National Network for Social Work Management, 2012.

25 Lawler J. Leadership in social work: a case of caveat emptor? Br J Soc Work 2007;37:123-41.

26 Haworth S, Miller R, Schaub J. Leadership in social work.

27 Avolio BJ, Waldman DA, Yammarino FJ. Leading in the 1990s: the four I's of transformational leadership. Jnl Euro Industrial Training $1991 ; 15$.
28 Alimo-Metcalfe B, Alban-Metcalfe RJ. The development of a new transformational leadership questionnaire. J Occup Organ Psychol 2001;74:1-27.

29 Bennis WG. Leadership theory and administrative behavior: the problem of authority. Adm Sci Q 1959;4:259-301.

30 Bennis W. The challenges of leadership in the modern world: introduction to the special issue. Am Psychol 2007;62:2-5.

31 Ruch G. Where have all the feelings gone? Developing reflective and relationship-based management in child-care social work. $\mathrm{Br} J$ Soc Work 2012;42:1315-32.

32 Tolleson Knee R, Folsom J. Bridging the crevasse between direct practice social work and management by increasing the transferability of core skills. Adm Soc Work 2012;36:390-408.

33 Fuller JB, Patterson CEP, Hester K, et al. A quantitative review of research on charismatic leadership. Psychol Rep 1996;78:271-87.

34 Jung DI, Sosik JJ. Transformational leadership in work groups: the role of empowerment, cohesiveness, and collective-efficacy on perceived group performance. Small Group Res 2002;33:313-36.

35 Lowe KB, Kroeck KG, Sivasubramaniam N. Effectiveness correlates of transformational and transactional leadership: a meta-analytic review of the mlq literature. Leadersh Q 1996;7:385-425.

36 Levac D, Colquhoun H, O'Brien KK. Scoping studies: advancing the methodology. Implement Sci 2010;5:69.

37 Arksey H, O'Malley L. Scoping studies: towards a methodological framework. Int J Soc Res Methodol 2005;8:19-32.

38 Tricco AC, Lillie E, Zarin W, et al. PRISMA extension for scoping reviews (PRISMA-ScR): checklist and explanation. Ann Intern Med 2018;169:467-73.

39 Braithwaite J, Mannion R, Matsuyama Y, et al. The future of health systems to 2030: a roadmap for global progress and sustainability. Int J Qual Health Care 2018;30:823-31.

40 Hutchison B, Levesque J-F, Strumpf E, et al. Primary health care in Canada: systems in motion. Milbank Q 2011;89:256-88.

41 Dinh JE, Lord RG, Gardner WL, et al. Leadership theory and research in the new millennium: current theoretical trends and changing perspectives. Leadersh Q 2014;25:36-62.

42 Offermann LR, Coats MR. Implicit theories of leadership: stability and change over two decades. Leadersh Q 2018;29:513-22. 